\title{
Erratum to: Design of Experiments-Based Monitoring of Critical Quality Attributes for the Spray-Drying Process of Insulin by NIR Spectroscopy
}

\author{
Morten Jonas Maltesen, ${ }^{1,2,3}$ Marco van de Weert, ${ }^{1}$ and Holger Grohganz ${ }^{1}$
}

\section{Erratum to: AAPS PharmSciTech \\ DOI:10.1208/s12249-012-9796-1}

In the citation to reprinted Figure 1, permission was omitted; Figure 1 was reprinted from reference 24 , Figure 4 , by permission.

The online version of the original article can be found at http:// dx.doi.org/10.1208/s12249-012-9796-1.

\footnotetext{
$\overline{{ }^{1} \text { Department of Pharmaceutics and Analytical Chemistry, Faculty of }}$ Pharmaceutical Sciences, University of Copenhagen, Copenhagen, Denmark.

${ }^{2}$ Biopharma Application Development, Novozymes Biopharma A/S, Krogshoejvej 36, 2880 Bagsvaerd, Denmark.

${ }^{3}$ To whom correspondence should be addressed. (e-mail: mjom@ novozymes.com)
} 